\title{
HBIM and Virtual Tools: A New Chance to Preserve Architectural Heritage
}

\author{
Anna Osello ${ }^{1, *}$, Greta Lucibello ${ }^{1, *(1)}$ and Francesco Morgagni 2,* \\ 1 Department of Structural, Geotechnical and Building Engineering (DISEG), Politecnico di Torino, \\ Corso Duca degli Abruzzi, 24, 10129 Turin, Italy \\ 2 Manital Spa, Via Giuseppe di Vittorio, 29, 10015 Ivrea, Italy \\ * Correspondence: anna.osello@polito.it (A.O.); greta.lucibello@polito.it (G.L.); \\ morgagni.francesco@manital.it (F.M.)
}

Received: 30 November 2017; Accepted: 17 January 2018; Published: 19 January 2018

\begin{abstract}
Nowadays, architectural heritage is increasingly exposed to dangers due to natural disasters or human invasive actions. However, management and conservation represent crucial phases within the life cycle of historical buildings. Unfortunately, the complexity of conservation practices and the lack of knowledge of historic buildings are the cause of an inefficient recovering process in case of emergencies. To overcome this problem, this research aims to ensure the preservation of relevant information through the use of building information modeling (BIM) methodology. By developing historic building information models (HBIMs), it is possible to enhance the architectural heritage. This represents an opportunity to incorporate digital media into the global heritage conservation field. To achieve this goal, a historical castle was selected as a case study; this unique piece of architecture is located in the Piedmont Region, close to city of Turin (Italy). The results show a direct relation between a historical digital model, finalized to the management of architectural and system components, and visualization tools. To conclude, the adoption of this strategy is an effective way to preserve and consult information using advanced visualization techniques based on augmented and virtual reality (AR and VR).
\end{abstract}

Keywords: architectural heritage; enhancement; management

\section{Introduction}

Conservation of architectural heritage is a process of knowledge, maintenance, management and enhancement aimed at preserving data of complex systems, such as historical buildings, which are the result of historical events, different architectural influences, changes in ownership, and transformations over time. Keeping alive these historical relics respects the past and the value acquired over centuries.

Nature challenges the identity of architectural heritage through earthquakes, seaquakes, floods and other natural catastrophes every day. Even man-made disasters put these buildings at risk: wars, neglect, or pollution are often the cause of irreparable damages to architecture. These events highlight serious problems in the reconstruction process and in the safeguard of the historical heritage. In fact, in emergencies, information availability concerning historical buildings is complex and there is risk of incorrect and disrespectful processes of recovery.

Knowledge is a main concern of historical buildings conservation, especially as far as unexpected events are concerned. An efficient strategy to preserve historical data is the well-known building information modeling (BIM), through the creation of a "building model containing any information about the construction" [1]. Within the heritage conservation field, BIM methodology is developing in "a new system of modeling historic structures" [2], giving rise to historic building information modeling (HBIM). The key objectives of this study are as follows: (1) data collection aimed at the 
management, maintenance, understanding, enhancement, and knowledge of a historical building; (2) creation of an as-built model to manage architectural and systems components; (3) data visualization tools based on augmented and virtual reality (AR and VR) to optimize and speed up the conservation practices and the recovery process in emergency. The proposed strategy is applied to a case study of a historical castle located in the Turin Province (Italy).

\section{Case Study}

\subsection{Territorial Framework}

The castle rises in a town close to the city of Turin (Figure 1). The context of the castle is surrounded by green areas and is characterized by a low concentration of buildings. Exceptionally, only the eastern area is characterized by many residential buildings of average height. The ground is slightly inclined, affecting the footprint of the castle. The interior distribution of the castle is structured around four atriums, historically called Cortile d'Onore, Corte Carrozze, Corte Rustica, and Corte Panoramica on different floors. The different parts of the castle present different features and heights, based on crucial transformations that have occurred over time.

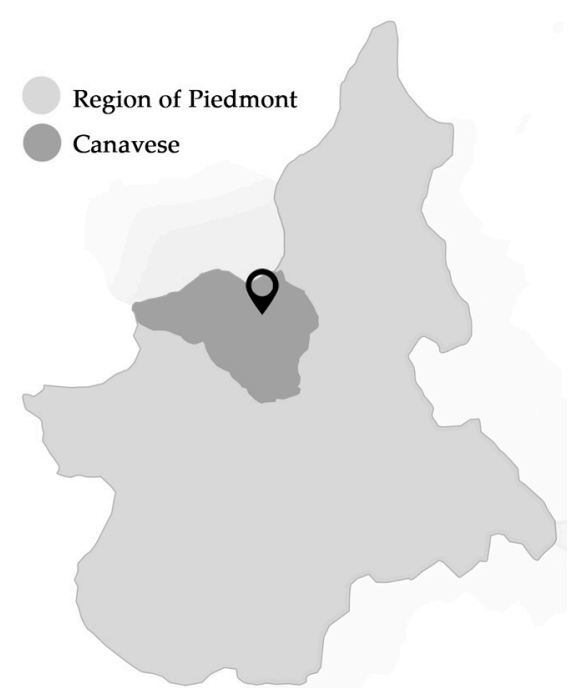

Figure 1. The location of the castle.

\subsection{Historical Framework}

Nowadays, the castle is owned by Manital (Ivrea, Italy), one of the most renowned solution providers specialized in design, management, and provision of facility management services in Italy. The company aims at restoring the castle, creating a multifunctional building that acts as a hotel, a gourmet restaurant, a spa, and a shopping center with several shops for the sale of typical products. Before becoming a reference point in the Canavese area, the castle was affected by significant changes. Its transformation is documented only by archival documents and paintings of the heritage site. The origins of the castle date back to the 16th century, when it was defined as "shelter" or "casa forte", an old farmhouse [3]. The shelter was turned into a building through a project developed by Carlo and Amedeo di Castellamonte in the following century. The modern structure of the castle, as shared by the Catasto Piemontese (1778), is due to several renovations that occurred in the 18th century and to an important restyling by the architect Giacomo Antonio Paracca. After the restoration of the decorations and the renovations of the interior spaces in the following century, the castle has been maintained in good condition until the owners decided to sell it. The building then remained in a condition of spoliation and abandonment until recent renovations were made. 


\subsection{The Research Project}

One of the most innovative aspects of the project is the application of the BIM methodology into its operation \& maintenance phase (O\&M); this was possible through a research project with a university, financed by Manital (Ivrea, Italy). This strategy is based on the creation of an HBIM as-built model by defining the level of detail and development (LOD) of the main components, a specific set of shared parameters, an appropriate system of coding and classification, and work-sharing tools. The strength of the parametric model consists in the possibility of promoting the management and conservation of heterogeneous information; furthermore, digital objects are linked to alphanumeric data through their tridimensional and scheduled representations, not only within the BIM software environment but also based on the data interoperability properties.

Therefore, the aim of this research project was the development of this case study as a "best practice" for future building management and maintenance. In this test, the experimentation of the VR and AR use aims to optimize data communication for different typologies of end-users and contexts.

\section{Results and Discussion}

\subsection{Data Collection}

The first result of this research is the processing of information related to the historical building analyzed. The data collection step takes several datasets into account. The cadaster documents prove the historical evolution of the building over time, allowing for the historical reconstruction described above. Another source of input is the analysis of 3D images from a stereoscopic camera, originating from point clouds, available through visualization software. These images have been very useful in visualizing the state of the castle before the restoration. Finally, the computer-aided design (CAD) drawings provided the as-built state as regards the architectural and system component, divided into their sub-disciplines (Figure 2).

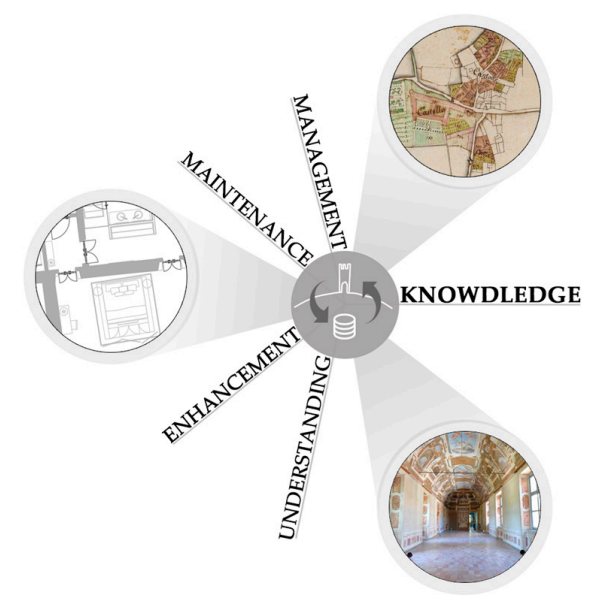

Figure 2. Datasets taken into account in data collection step.

The aim achieved in this first step is data optimization, creating a hierarchy of information according to the BIM model goals. In fact, the amount of data available has been filtered according to the parameters useful for space management and system maintenance. At this stage, the result allows for a definition of the level of the knowledge that the BIM model must provide to users in order to optimize the conservation process and the management of the historical building studied.

\subsection{Architectural Modeling for Space Management}

BIM software, initially used to manage new building construction, may represent an opportunity for heritage documentation and conservation management [4]. Every historical building has its own 
architectural identity due to singular past and historical changes over time. Therefore, architectural heritage is characterized by very complex and irregular shapes, mostly not in accordance with classical geometrical laws. In the specific case of the castle, the great amount of walls changes thickness over their height and length. Furthermore, some elements represent the result of their deterioration over time, revealing complex and particular shapes. Their modeling is even harder with common software of modeling and requires a considerable amount of time. In fact, the criticism of the current research in this field is the loss of pre-defined libraries for modeling existing and historic buildings [5]. The key to realizing a model that strictly follows the project aim is to find a compromise between modeling and information. To achieve this result, many strategies of modeling have been adopted in the same BIM model. In fact, for each complex element of the building, different solutions have been tested. Therefore, the architectural components have LODs that depend on the project aim. This strategy is one of the innovative aspects of this research. In fact, the focus of the modeling is not the creation of new library objects for a historic building, such as in various projects of Baik et al. (2014) [6], Chevrier et al. (2010) [7], or Murphy [2]. The modeling of architectural elements with high levels of detail is not necessary in order to use the model in the O\&M phase. The greater effort in this step must be reserved for the information linked to the BIM objects.

\subsection{Mechanical Electrical Plumbing (MEP) Modeling for Maintenance Systems}

Maintenance systems make working and living environments comfortable and safe. Architecture and maintenance systems must be equally considered not only in the planning practice but also in the construction phase. In historical buildings, this balance is even more complex, because there are many architectural constraints. In the case of the castle, the core of the project is the effort made to integrate plants and architectural components, such that the existing structures are respected. In fact, the technical rooms are located in the attic, in the basement, or in rooms without architectural value [3]. Therefore, the spaces for technological sections are compact and tight, complicating the realization and the modeling of the project. The understanding of systems design is fundamental to building knowledge. Especially in emergencies, it becomes the key to having a safe building and optimizing interventions of recovery. In this phase of the project, the main goal was the inclusion of information about maintenance system components. The geometrical and alphanumerical data, i.e., the coding of system elements or rooms, were planned in agreement with the management system traditionally used by the company. The management software is sufficiently interoperable with a BIM model: it retains all parametric properties, updates the changes made in the model, and visualizes its three-dimensionality. Therefore, the interoperability between an as-built model and specific software for the building management and maintenance ensures the durability of the datasets, achieving an important result for the O\&M phase.

\subsection{Visualization Tools for Building Management and Conservation}

In recent years, economic and cultural challenges have sparked interest in smart technologies for the building life cycle, in particular the O\&M phase. In this step, BIM plays a fundamental role. In emergency contexts, the need to preserve policies and sustainable management, conservation, cost-effective maintenance, and restoration techniques can benefit from HBIM. In fact, the historic building information model can be used in immersive and interactive environments to extract and visualize useful information for specialists in the architecture, engineering, and construction (AEC) industries and for cultural heritage documentation. This process plays an essential role in the creation of knowledge and the preservation of cultural heritage [8].

The research tests the cutting-edge technologies in the historic building information model, which has been transformed into a model for mobile apps based on AR and VR. The first result on data visualization is the interaction with data contained in the model, allowing different teams to work together in different places. This interaction was possible through an online workspace such as Autodesk A360 (San Rafael, CA, USA), where users can share the BIM model, communicate, 
and receive feedback in real time (Figure 3). The possibility of locating the faults simultaneously in the reality and in the model allows for immediate, located, and specific communication. In addition, the use of applications for mobile devices enables reports in case of malfunctioning everywhere, offline too.

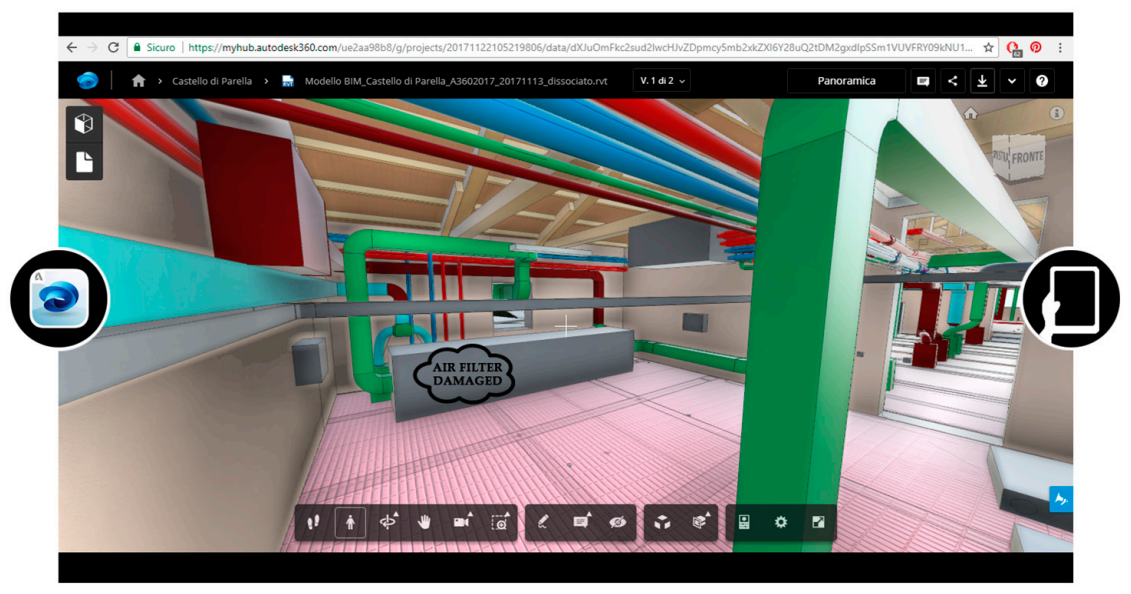

Figure 3. Comment to report malfunctioning.

The use of technologies based on VR allows one to interact with the building and to schedule repair operations without being on-site. This opportunity is fundamental, especially in case of emergency, because it allows one to identify criticisms and program-specific interventions. Another plus of this technology is the updating of data in the virtual model, because there is no loss of parametric proprieties. In fact, the BIM model can be reloaded on the online platform, allowing for the updating of modified data in real time.

One of the objectives of this research is to optimize and speed up the conservation practices and the recovery process during emergency. To achieve this goal, two of the technologies tested are the headsets Oculus Rift (Oculus VR, Menlo Park, CA, USA) and HTC Vive (HTC, New Taipei City, Taiwan). After the BIM model was exported into Filmbox (.fbx) (San Rafael, CA, USA), a proprietary file format for exchanging data between digital content applications, the three-dimensional model was imported in several VR software. Moving within the virtual models and approaching the elements, it is possible to visualize the relative properties, attached here as images of the virtual environment (Figures 4 and 5). Furthermore, the greatest advantage of BIM is the precise location of systems within the building, which helps in reducing further damage due to uncoordinated and unconscious interventions. From an economic point of view, the opportunities explained above represent a remarkable advantage: a deep knowledge of the building allows for a smart use of resources. The main criticism found in the use of these technologies is represented by the loss of parametric properties of BIM objects. "Smart objects" are transformed into shapes and surfaces, and all parameters are missing. Despite this criticism, the versatility of BIM leads to successful results. In fact, the same three-dimensional parametric model created for building management and system maintenance is also used for data visualization. The open file formats, such as the industry foundation classes (IFCs), would certainly be a better solution to involve the AR and VR in the BIM process. Nowadays, however, the use of open file formats causes a considerable loss of data, achieving results not already successful. Future research will improve the efficiency of neutral data formats and accordingly the interoperability process between modeling and visualization software.

Finally, the last result concerning data visualization is based on AR applications. The test applied for this research aimed to promote historical building conservation, appending virtual information to the real world [9]. In fact, this AR technique allows one to localize the system components hidden behind pieces of furniture or architectural barriers within a castle room. The virtual model overlaps its real position in real time (Figure 6). The marker to visualize the content in AR is the georeferencing of 
the virtual model itself. Then, the maintainers can work in a non-invasive way, preventing damage to architectural elements.

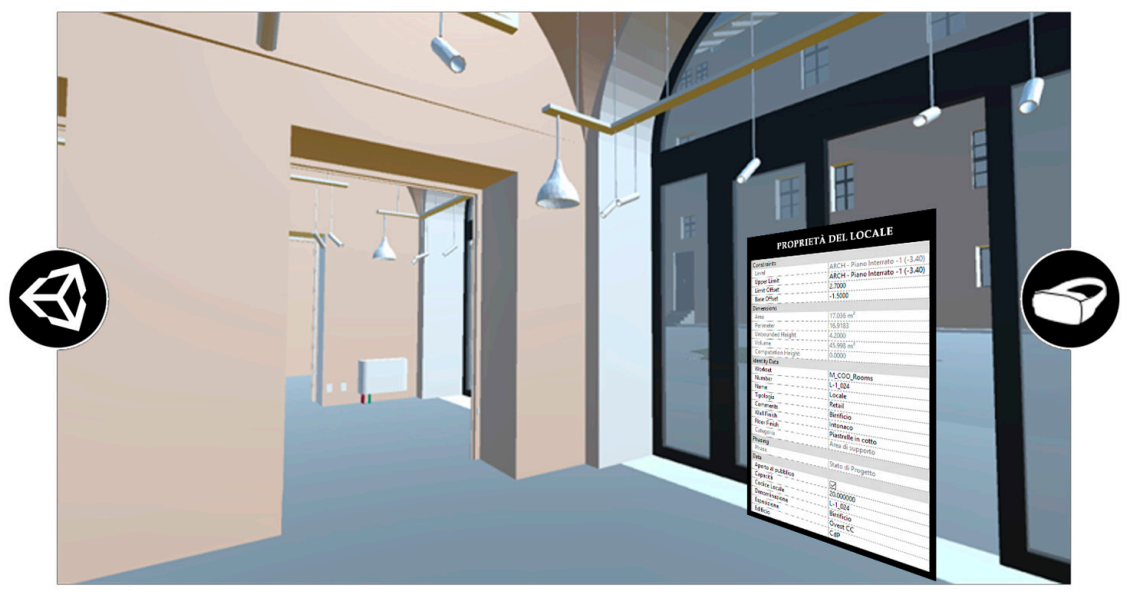

Figure 4. Room properties visualization with Oculus Rift.

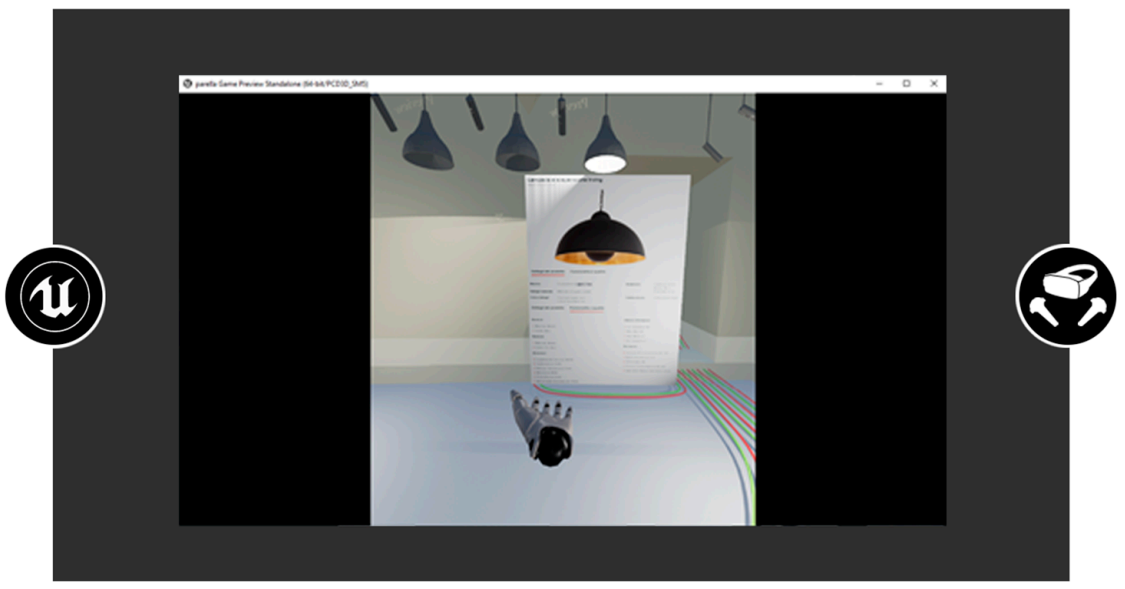

Figure 5. Lamp properties visualization with HTC Vive.

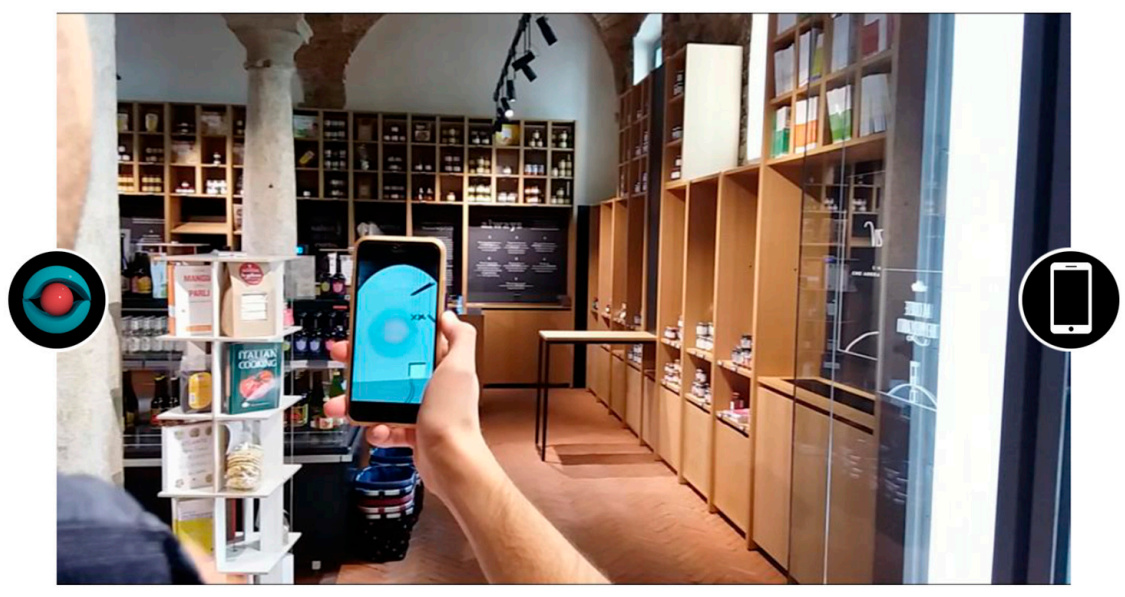

Figure 6. Systems visualization with an augmented reality (AR) media app. 


\section{Materials and Methods}

To achieve the above results, different proceedings and interoperability processes were tested on the case study. In fact, the modeling and visualization tools are focused on the management, maintenance, and conservation of the historical building, in order to find successful strategies in case of emergency.

One of the project results is the architectural and Mechanical Electrical Plumbing (MEP) modeling, according to the LOD necessary to achieve the model goal. A three-dimensional model was designed using the BIM software Autodesk Revit (.rot). The modeling of architectural elements was simplified, without significantly altering the values related to the management and maintenance of the spaces, such as the calculation of the rooms and the materials areas. For this reason, each BIM object was described to a proper LOD, depending on the specific strategy of modeling too. Referring to AIA Document G202-2013 (Project Building Information Modeling Protocol Form), the Figure 7 shows the different LODs of BIM objects.
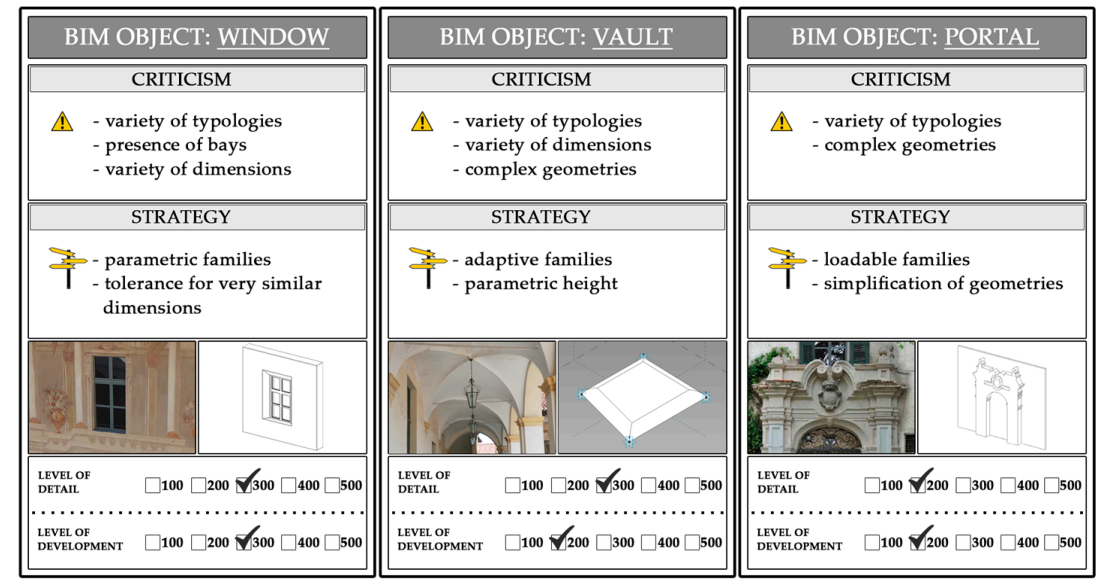

Figure 7. Different strategies adopted for architectural building information modeling (BIM) objects.

As shown in the figure below, the irregular shapes of the castle walls have raised criticisms; specific strategies are being adopted in a timely fashion and analyzed case by case. The use of three different solutions for the creation of the same object helped us to meet our BIM model goal (Figure 8). In fact, the area of the rooms in the model differs by less than $2 \%$ compared to the real area of the locals. In this case, the LODs changed within the same object family, according to the strategy of modeling adopted.

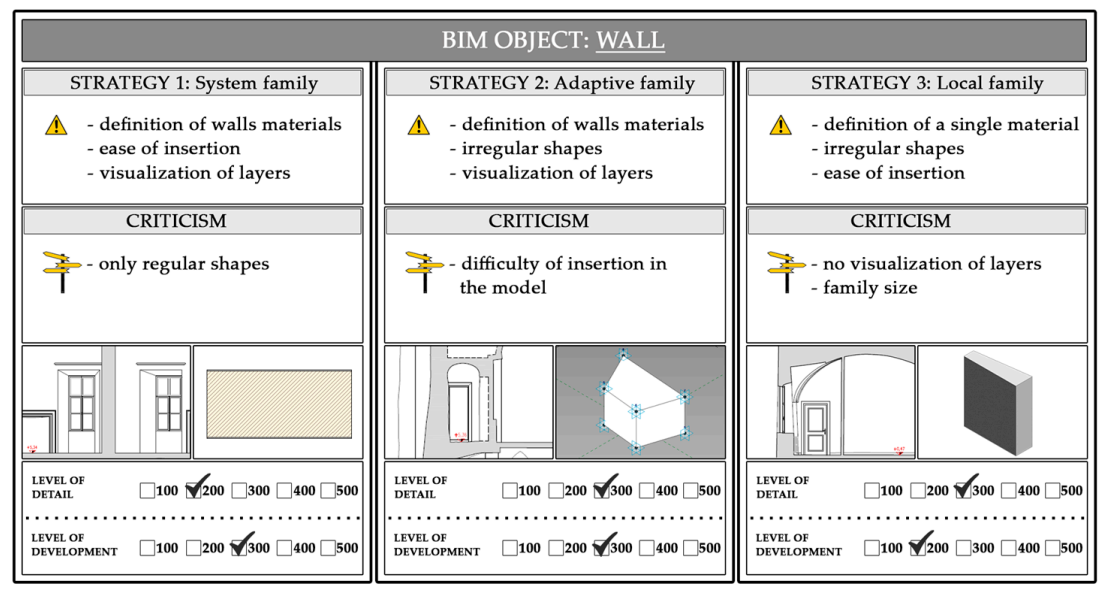

Figure 8. Different strategies adopted for wall Revit family. 
The MEP objects, as do architectural elements, have different LODs. Each plant component has different criteria of representation depending on the detail level of the view. The elements are visualized with a two-dimensional symbol at a coarse level of detail —at a medium and fine detail level, they are visualized with a three-dimensional object. This representation allows the maintainers to find a correspondence with standardized symbolism (Figure 9).

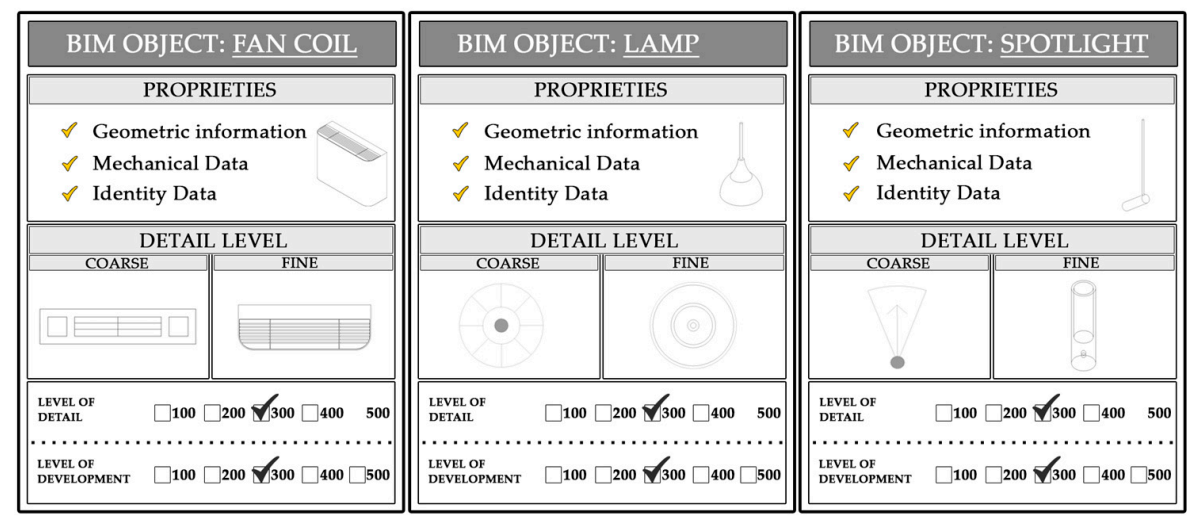

Figure 9. Different detail levels for system objects.

The properties of MEP objects were entered within the model mainly through shared parameters. These data are divided by geometrical information, mechanical or electrical data, and indications about the product. The properties of the elements include external links as well, for example on a technical datasheet or website of the manufacturer.

The result that required greater effort was the definition of the methods used for data visualization. According to Figure 10, the interaction between the BIM model and the virtual environment requires fragmented steps. For this research project, an interoperability process was tested to achieve the results.

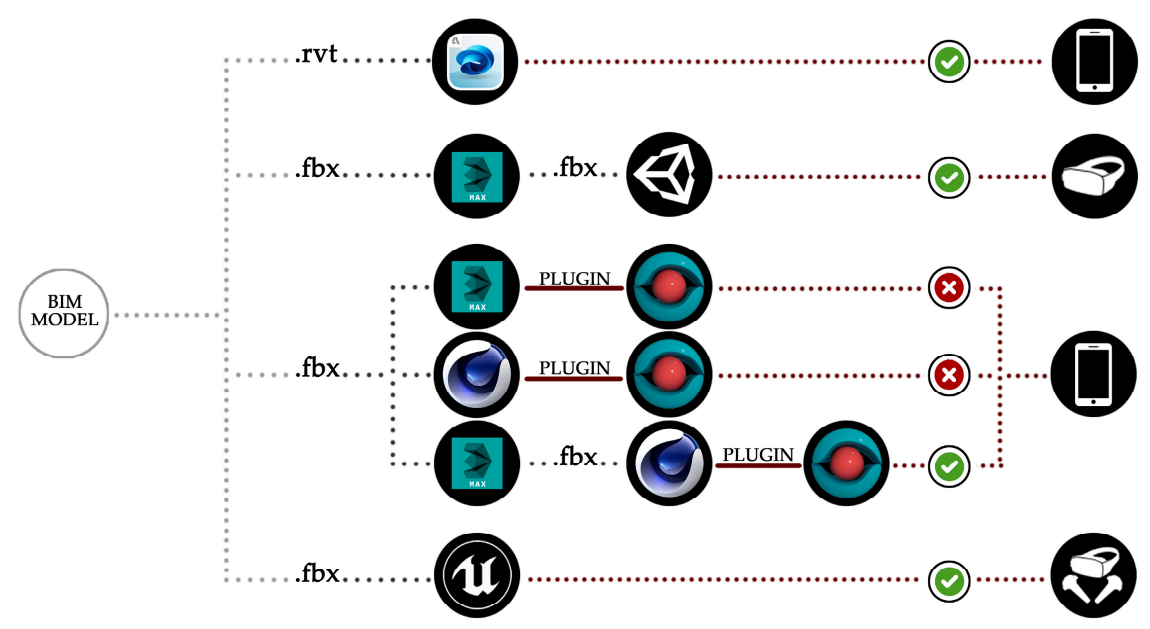

Figure 10. Interoperability tests for data visualization in AR and virtual reality (VR).

The first test was carried out on the online platform Autodesk A360. The BIM-oriented software was accessed with an Autodesk account, then the program was loaded in native format (.rvt); finally a new project was created. This ensured that the BIM properties were retained. The project could be shared with other users inserting their e-mail address.

All views, sheets, schedules, and elements properties included in the BIM model could be visualized once the model was opened. In fact, each architectural or MEP object was searchable. In addition, it was possible to walk virtually within the building. In this way, the insertion of any 
comments or notes was facilitated. In fact, the virtual person could approach the failed equipment and insert a text in proximity to the element in order to report the fault. The project sharing allowed for interaction between different users involved in the process. In fact, comment insertion was reported to other users via notification, creating efficient interaction between stakeholders.

More advanced strategies of data visualization were tested. The BIM model was exported in .fbx format. The major criticism here is the loss of information linked to smart and parameterized objects. In fact, after exportation, these objects became three-dimensional surfaces, losing the BIM benefits. Unity 3D (Unity Technologies, San Francisco, CA, USA) was used to navigate the model with the headset Oculus Rift. In order to better control the model and materials in Unity 3D, it is recommended that the file is imported in Autodesk 3ds Max. This importation could be done through the Import or Link commands: in this specific case, it was done via a link connection. 3ds Max provides options for combining Revit and . $f b x$ entities. In order to assign the materials in the most complete way possible, the Revit model was combined by Family Type.

After exporting the .fbx file from 3ds Max, the model was loaded in Unity 3D. To start the virtual model navigation, the model propriety "Generate Colliders" was set; this is useful for defining the shape of an object for the purposes of physical collisions (Figure 11).

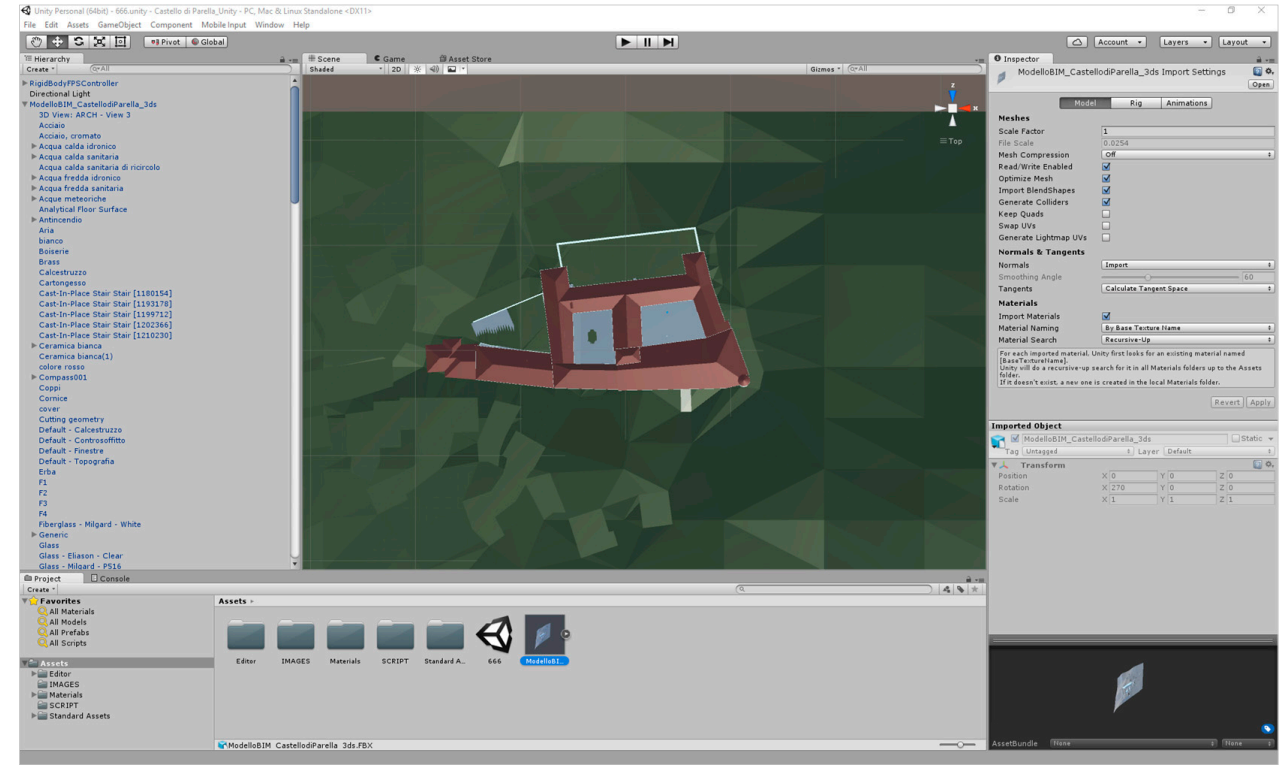

Figure 11. Setting of model properties in Unity 3D.

The next step was the input of scripts in order to link information to a model shape and to visualize them in a specific location. The first script was placed in a User Interface (UI) object, called the canvas. It is a framework that allows one to insert different virtual information, such as texts, images, or videos inside Canvas. The second script was associated with GameObject, which is an invisible object that allows one to switch a particular action on or off. Therefore, when the virtual person enters in the volume of GameObject, the information linked to the canvas appears in the virtual environment. In this test, the information associated with the canvas are images with BIM object properties, such as room parameters or circuits linked to a specific electric board.

The third test in the virtual environment is based on the use of a headset HTC Vive for the daily management and maintenance of a building. To create an immersive environment, numerous interoperability processes were tested. The Unreal Engine software was used because it is sufficiently interoperable with the $f b x$ format exported by Revit. The next step was the input of a camera within a castle room. The aim was to navigate the virtual model to visualize information linked to questioning objects, for example the technical datasheet. To associate this image with a surface, the strategy 
adopted was to create a transparent material with glass-like properties and insert the figure as a texture. The surface was located near the terminal (Figure 12).

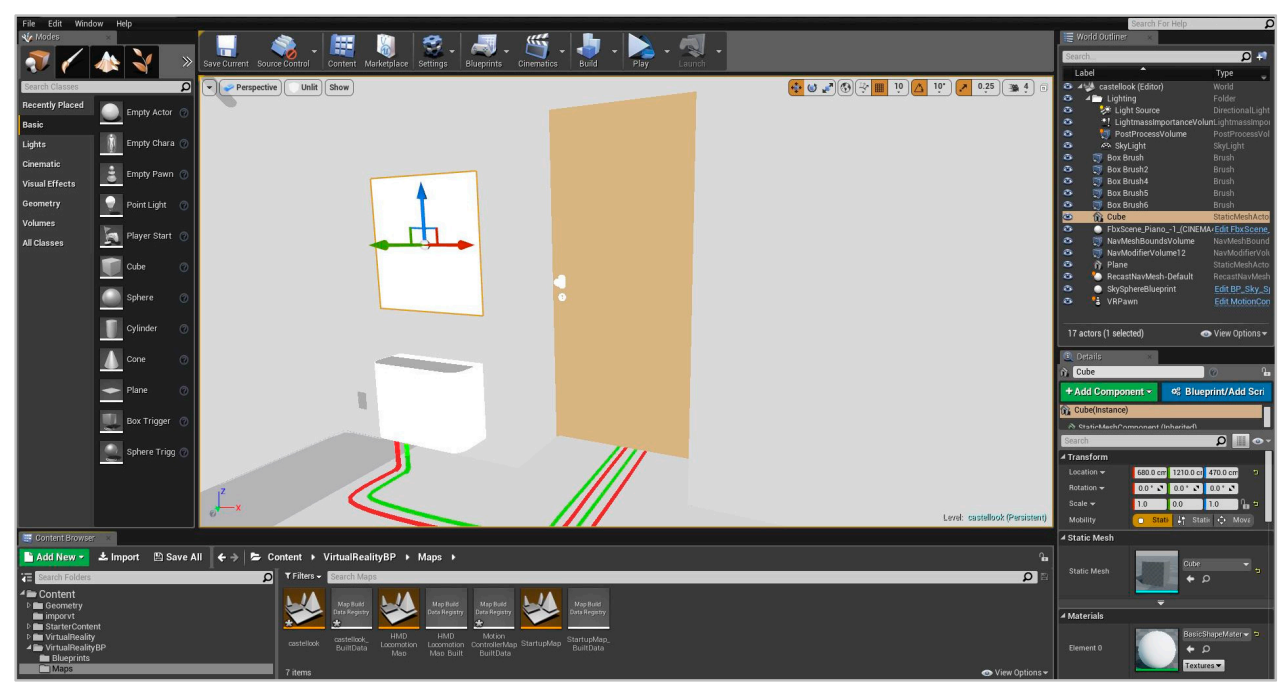

Figure 12. Positioning of a surface close the terminal in Unreal Engine.

In order to visualize the image of the technical datasheet, it was necessary to create a specific script. This allowed one to select, with a laser controller, the surface and visualize the associated image.

The last test of this research was based on the use of AR. Different proceedings and interoperability processes were tested (Figure 10). Additionally, the model was exported from Revit as an .fbx file and imported into Autodesk 3ds Max, combining it with the tool Materials. In this software, the model was lightened by unnecessary elements. The model was then imported into Cinema $4 \mathrm{D}$, always in .$f b x$ format, because material proprieties are not transferred in the AR-media plugin using $3 \mathrm{ds}$ Max. Through the AR-media plugin, the 3D model was exported in armedia format, in order to display it with an AR-media app for mobile devices. The model was then georeferenced with the castle coordinates (Figure 13). At this stage, with the smartphone app, the maintainers within the building could navigate the virtual model. After orienting the virtual model just like in the reality, users could locate the hidden terminals [10].

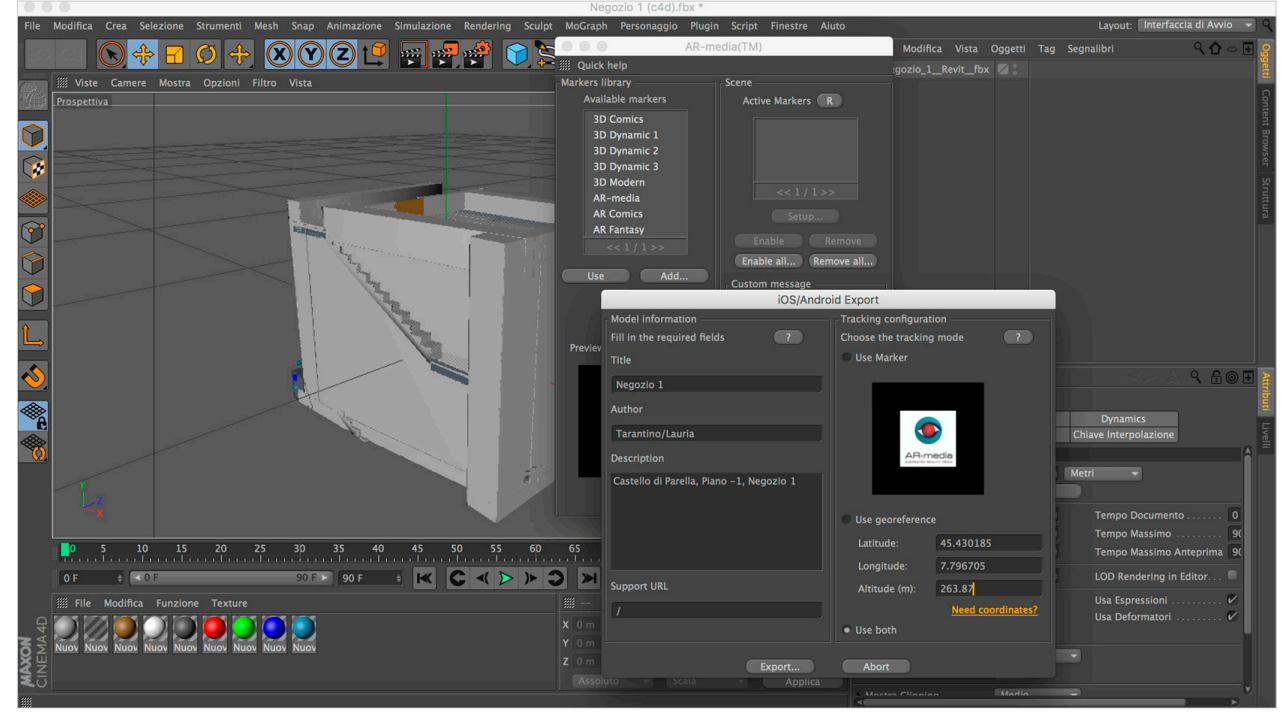

Figure 13. Georeferencing of the model in Cinema 4D. 


\section{Conclusions}

The goals introduced at the beginning of this study were achieved with successful results. The application of the methodology to a real case study dealt with tangible necessities and real users. The participation of the company in the process was crucial in the achievement of the project aims. In fact, ensuring a constant dialogue, the compromises gained directs future efforts.

The first result based on data collection allowed for building knowledge. This step has been proven essential for the management, maintenance, understanding, and enhancement of a building. The architectural and system component modeling required particular attention due to building typology. In fact, being a historical building, an appreciable amount of time was spent choosing the best modeling strategies.

The result was an HBIM model where the architectural elements are simplified, but ensuring the accuracy of values related to space management and component conservation. In addition, the MEP modeling was focused on the amount of data linked to the system elements, leaving aside the geometrical correspondence with reality. In this way, the modeling was consistent with the aim of the project, optimizing the management and maintenance processes of the building.

The data visualization step was the last focus of this project. The conservation practices and the renovation process in emergencies were optimized through the experimentation and development of augmented and virtual reality tools. The proposed strategies highlight certain interoperability problems. Further research within this field must be carried out, exploiting new visualization techniques; only this approach will simplify the process.

These results are possible outputs retrieved from the adoption of BIM methodology in the conservation field. Such methodology can be considered an efficient solution to preserving data and promoting building management in emergencies.

Acknowledgments: This research was funded by a Company of Facility Management. All authors are pleased to thank the Master students for permission to exhibit their work.

Author Contributions: Anna Osello and Francesco Morgagni conceived and designed the experiments; Greta Lucibello performed the experiments; Greta Lucibello analyzed the data; Anna Osello and Francesco Morgagni contributed reagents/materials/analysis tools; Greta Lucibello wrote the paper.

Conflicts of Interest: The authors declare no conflict of interest.

\section{References}

1. BIPS. 3D Working Method 2006; Digital Construction: Ballerup, Denmark, 2007; p. 12.

2. Murphy, M.; McGovern, E.; Pavia, S. Historic building information modelling (HBIM). Struct. Surv. 2009, 27, 311-327. [CrossRef]

3. Serraino, M.; Lucchi, E. Energy efficiency, heritage conservation, and landscape integration: The case study of the San Martino Castle in Parella (Turin, Italy). Energy Procedia 2017, 133, 424-434. [CrossRef]

4. Hichri, N.; Stefani, C.; De Luca, L.; Veron, P. Review of the "AS-BUILT BIM" Approaches. Int. Soc. Photogramm. Remote Sens. 2013, XL-5/W1, 107-111. [CrossRef]

5. Dore, C.; Murphy, M. Current state of the art Historic Building Information Modelling. Int. Arch. Photogramm. Remote Sens. Spat. Inf. Sci. 2017, XL22-2/W5, 190. [CrossRef]

6. Baik, A.; Alitany, A.; Boehm, J.; Robson, S. Jeddah Historical Building Information Modelling "JHBIM"-Object library. Int. Ann. Photogramm. Remote Sens. Spat. Inf. Sci. 2014, II-5, 41-47. [CrossRef]

7. Chevrier, C.; Charbonneau, N.; Grussenmeyer, P.; Perrin, J.-P. Parametric documenting of built heritage: 3D virtual reconstruction of architectural details. Int. J. Architect. Comput. 2010, 8, 131-145. [CrossRef]

8. Barazzetti, L. Banfi, F. Historic BIM for mobile VR/AR applications. In Mixed Reality and Gamification for Cultural Heritage; Ioannides, M., Magnenat-Thalmann, N., Papagiannakis, G., Eds.; Springer: Cham, Switzerland, 2017; pp. 271-290.

9. Chan-Sik, P.; Do-Yeop, L.; Oh-Seong, K.; Xiangyu, W. A framework for proactive construction defect management using BIM, augmented reality and ontology-based data collection template. Autom. Constr. $2013,33,61-71$. 
10. Lauria, S.; Tarantino, T. BIM, Realtà Virtuale e Aumentata per la Gestione Della Manutenzione. Il Caso Studio: Il Castello di Parella. Master's Thesis, Degree in Sustainable Architecture, Polytechnic University of Turin, Turin, Italy, September 2017. (CC BY) license (http:/ / creativecommons.org/licenses/by/4.0/). 